\title{
Background incidence rates of adverse events of special interest related to COVID-19 vaccines in Ontario, Canada, 2015 to 2020, to inform COVID-19 vaccine safety surveillance
}

Sharifa Nasreen ${ }^{1,2}$, Andrew Calzavara ${ }^{2}$, Sarah A. Buchan ${ }^{1,2,3}$, Nisha Thampi ${ }^{3,4}$, Caitlin Johnson $^{3}$, Sarah E. Wilson ${ }^{1,2,3}$, and Jeffrey C. Kwong ${ }^{1,2,3,5,6}$ on behalf of the Canadian Immunization Research Network (CIRN) Provincial Collaborative Network (PCN) Ontario investigators

\section{Affiliations:}

${ }^{1}$ Dalla Lana School of Public Health, University of Toronto, Toronto, ON, Canada

${ }^{2}$ ICES, Toronto, ON, Canada

${ }^{3}$ Public Health Ontario, ON, Canada

${ }^{4}$ Department of Pediatrics, Faculty of Medicine, University of Ottawa, Ottawa, ON, Canada

${ }^{5}$ Department of Family and Community Medicine, University of Toronto, Toronto, ON, Canada

${ }^{6}$ University Health Network, Toronto, ON, Canada

\section{Corresponding author:}

Jeffrey C. Kwong

Senior Scientist, ICES

G1 06, 2075 Bayview Avenue

Toronto, Ontario, Canada, M4N 3M5

jeff.kwong@utoronto.ca

Phone: (416) 480-4055 x1-7665 Fax: (416) 480-6048 


\begin{abstract}
Background: Background incidence rates are critical in pharmacovigilance to facilitate identification of vaccine safety signals. We estimated background incidence rates of nine adverse events of special interest related to COVID-19 vaccines in Ontario, Canada.
\end{abstract}

Methods: We conducted a population-based retrospective observational study using linked health administrative databases for hospitalizations and emergency department visits among Ontario residents. We estimated incidence rates of Bell's palsy, idiopathic thrombocytopenia, febrile convulsions, acute disseminated encephalomyelitis, myocarditis, pericarditis, Kawasaki disease, Guillain-Barré syndrome, and transverse myelitis during five pre-pandemic years (20152019) and 2020.

Results: The average annual population was 14 million across all age groups with $51 \%$ female. The pre-pandemic mean annual rates per 100,000 population during 2015-2019 were 43.9 for idiopathic thrombocytopenia, 27.8 for Bell's palsy, 25.0 for febrile convulsions, 22.8 for acute disseminated encephalomyelitis, 11.3 for myocarditis/pericarditis, 8.6 for pericarditis, 2.9 for myocarditis, 1.9 for Guillain-Barré syndrome, 1.7 for transverse myelitis, and 1.6 for Kawasaki disease. Females had higher rates of acute disseminated encephalomyelitis and transverse myelitis while males had higher rates of myocarditis, pericarditis, and Guillain-Barré syndrome. Bell's palsy, acute disseminated encephalomyelitis, and Guillain-Barré syndrome increased with age. The mean rates of myocarditis and/or pericarditis increased with age up to 79 years; males had higher rates than females: from 12-59 years for myocarditis and $\geq 12$ years for pericarditis. Febrile convulsions and Kawasaki disease were predominantly childhood diseases and generally decreased with age.

Conclusions: Our estimated background rates will permit estimating numbers of expected events for these conditions and facilitate detection of potential safety signals following COVID-19 vaccination.

Key words: Background rates, Incidence rates, Adverse events, COVID-19, Vaccine safety 
medRxiv preprint doi: https://doi.org/10.1101/2022.01.12.22269169; this version posted January 16, 2022. The copyright holder for this preprint (which was not certified by peer review) is the author/funder, who has granted medRxiv a license to display the preprint in perpetuity.

It is made available under a CC-BY-NC-ND 4.0 International license.

\section{Introduction}

Health Canada initially authorized BNT162b2 (Pfizer-BioNTech Comirnaty) and mRNA-1273

(Moderna SpikeVax) COVID-19 vaccines for use in individuals aged $\geq 16$ and $\geq 18$ years, respectively, in December 2020. ${ }^{1}$ The authorization was later expanded for use of BNT162b2 in adolescents aged 12-15 years in May 2021, and for use of mRNA-1273 in 12-17 years in August 2021. ${ }^{2}$ Health Canada authorized adenovirus vector-based ChAdOx1 COVID-19 vaccines (AstraZeneca Vaxzevria and COVISHIELD) in February 2021 for use in individuals aged $\geq 18$ years. ${ }^{2}$ While Ad26.COV2.S (Johnson \& Johnson's Janssen) vaccine was also authorized by Health Canada in March 2021 for use in individuals aged $\geq 18$ years, it has not been used widely in Canada. ${ }^{3}$ Very rare cases of thrombosis with thrombocytopenia have been reported globally following receipt of adenovirus vector vaccines. ${ }^{4}$ Rare adverse events such as myocarditis and pericarditis have been reported after receiving the mRNA vaccines in Canada and internationally, particularly among adolescent males and young adults. ${ }^{5-13}$ The observed number of myocarditis/pericarditis cases was higher than the expected number of cases among individuals aged 12-39 years in the US and Canada. ${ }^{14-16}$ Facial palsy, including Bell's palsy has also been reported after the receipt of an mRNA COVID-19 vaccine, predominantly in adults aged 18-44 years and rarely in children aged $\leq 11$ years. ${ }^{17}$ Rare cases of Guillain-Barré Syndrome (GBS) have been reported following vaccinations with ChAdOx1 and Ad26.COV2.S vaccines. $^{18-20}$

On 26 October 2021, the US Food and Drug Administration recommended emergency use authorization for a two-dose primary series of BNT162b2 using one-third (10- $\mu \mathrm{g})$ of the teen and adult dose in children aged 5-11 years. ${ }^{21}$ The US Centers for Disease Control and Prevention recommended this vaccine for children aged 5-11 years on 2 November $2021 .^{22}$ On 19 November 2021, Health Canada authorized the BNT162b2 pediatric vaccine for use in children aged 5-11 years and on the same day Canada's National Advisory Committee on Immunization issued their statement recommending its use. ${ }^{23} 24$ The phase $2 / 3$ clinical trial of BNT162b2 in children aged 5-11 years observed no serious adverse events attributed to the vaccine, including myocarditis/pericarditis. However, only 1,518 vaccinated children and 750 children in the placebo group contributed to the safety data with at least 2 months of follow-up after receipt of the second dose; an additional 1,509 vaccinated children and 788 children in the placebo group 
with only 2.4 weeks of median follow-up after receipt of the second dose contributed to supplemental safety data. Thus, post-licensure surveillance is critical to identify vaccine safety signals for myocarditis, pericarditis, and other rare adverse events of special interest (AESI) relevant to this population. ${ }^{25}$

Background rates facilitate the identification of vaccine safety signals by permitting the calculation of expected numbers of events, which can be compared to observed events. ${ }^{26-29}$ Background rates may vary by calendar time, age, sex, socioeconomic status, and geography. ${ }^{29}$ There is a lack of data on recent background rates of potential AESI to inform COVID-19 vaccine safety surveillance in Ontario. We previously reported the background incidence rates of selected thromboembolic and coagulation disorders in Ontario. ${ }^{30}$ In this paper we report the background incidence rates of hospitalizations and emergency department visits for nine additional AESI during five pre-pandemic years (2015-2019) and 2020 in Ontario, Canada. The rates in children are presented according to vaccine eligible age bands to facilitate safety signal assessment in the pediatric population, specifically in children aged $<12$ years.

\section{Methods}

We conducted a population-based retrospective observational study using linked health administrative databases from Ontario, Canada and analyzed at ICES (formerly the Institute for Clinical Evaluative Sciences). We identified hospitalizations and emergency department visits for 9 AESI: Bell's palsy, idiopathic thrombocytopenia, febrile convulsions, acute disseminated encephalomyelitis, myocarditis, pericarditis, Kawasaki disease, Guillain-Barré syndrome, and transverse myelitis. Cases were identified using diagnostic codes from the International Statistical Classification of Diseases and Related Health Problems, Tenth Revision, Canada $(I C D-10-C A)^{31}$ (Supplemental Table S1). Where available, we used codes that have been validated and/or used in previous studies. ${ }^{26} 3233$ Hospitalizations and emergency department visits were identified from the Canadian Institute for Health Information (CIHI) Discharge Abstract Database (DAD) and CIHI's National Ambulatory Care Reporting System, respectively. For hospitalizations, we included cases where an ICD-10-CA code of interest was present on admission and of primary relevance to the stay, and not listed as a secondary diagnosis, comorbidity, or as part of the medical history. We included emergency department 
visits where a code of interest was present in any diagnosis field. As Bell's palsy cases are often treated in outpatient settings, we also included outpatient Bell's palsy cases identified from the Ontario Health Insurance Plan physician billing claims database, and included these in a broader case definition combining hospitalizations, emergency department visits, and outpatient visits. For idiopathic thrombocytopenia, acute disseminated encephalomyelitis, and transverse myelitis, we also used narrow definitions to estimate conservative rates for these conditions (Supplemental Table S1). We included only new cases after a 365-day period without the same condition (i.e., group of codes included in each AESI definition) for each individual. Thus, one episode per individual was included across all data sources; multiple episodes of an AESI for an individual within a 365-day period were not included. We obtained information on age and sex from Ontario's Registered Persons Database, which contains all Ontarians registered under the Ontario Health Insurance Plan.

\section{Statistical analysis}

For each AESI, we calculated annual incidence rates per 100,000 population by age group (0-4, 5-11 years, 12-15, 16-19, 20-24, 25-29, 30-39, 40-49, 50-59, 60-69, 70-79 and $\geq 80$ years), by sex, and by age group and sex during each of five pre-pandemic years (2015-2019) and 2020. We also estimated the overall mean annual incidence for 2015-2019. The rates of idiopathic thrombocytopenia using the narrow definition are presented for 0-29 years only because the rates for $\geq 30$ years have been reported previously. ${ }^{30} \mathrm{We}$ calculated monthly average rates for 2015-2019 to examine seasonality in children aged 0-11 years. We used Statistics Canada Census and intercensal population estimates as denominators. The $95 \%$ confidence intervals (CIs) were calculated using a gamma distribution. ${ }^{34}$

\section{Results}

\section{Rates across all ages}

The study population included approximately 85 million person-years of observation for all age groups from 2015 to 2020 . The average annual study population was 14 million with $51 \%$ female. 
medRxiv preprint doi: https://doi.org/10.1101/2022.01.12.22269169; this version posted January 16, 2022. The copyright holder for this preprint (which was not certified by peer review) is the author/funder, who has granted medRxiv a license to display the preprint in perpetuity.

It is made available under a CC-BY-NC-ND 4.0 International license .

During 2015-2019, the overall mean incidence rate of hospitalizations and ED visits for both sexes and all ages was highest for idiopathic thrombocytopenia $(43.9$ per 100,000) and lowest for Kawasaki disease (1.6 per 100,000). The mean incidence rates per 100,000 population for other AESI were 27.8 for Bell's palsy, 25.0 for febrile convulsions, 22.8 for acute disseminated encephalomyelitis, 11.3 for myocarditis/pericarditis, 8.6 for pericarditis, 2.9 for myocarditis, 1.9 for Guillain-Barré syndrome, and 1.7 for transverse myelitis. The mean rate of Bell's palsy was 71.3 per 100,000 population when cases identified in outpatient physician offices were included. Rates were generally consistent over time (Table 1). Rates were lower in 2020 than during the pre-pandemic years for febrile convulsions, acute disseminated encephalomyelitis, and GuillainBarré syndrome. The annual rates of myocarditis/pericarditis, myocarditis, and pericarditis across all age groups were relatively stable during 2017-2019, and slightly lower in 2020 (Supplemental Table S6). Rates of pericarditis were approximately 3 times higher than rates of myocarditis.

Mean pre-pandemic incidence rates of acute disseminated encephalomyelitis and transverse myelitis tended to be higher for females than males (Figure 1). In contrast, mean pre-pandemic rates of myocarditis, pericarditis, and Guillain-Barré syndrome were higher for males than females. Rates for Bell's palsy, acute disseminated encephalomyelitis, myocarditis, pericarditis, and Guillain-Barré syndrome generally increased with age. Mean pre-pandemic rates of idiopathic thrombocytopenia increased with age after 24 years of age, and was higher in males than females at $\geq 40$ years. Mean pre-pandemic rates of myocarditis/pericarditis were similar for females and males up to 11 years of age, then diverged to be higher for males than females, with two peaks in males at 16-24 years and $\geq 70$ years (Figure 1). The mean rates of myocarditis were higher for males than females aged 12-59 years; rates of pericarditis were higher for males aged $\geq 12$ years. Febrile convulsions and Kawasaki disease were predominantly childhood diseases and generally decreased with age.

\section{Rates in children aged 0-11 years}

The study population included approximately 10.7 million person-years of observation among children aged 0-11 years from 2015 to 2020; 60\% of the study population was aged 5-11 years. The average annual study population was 1.8 million, with $49 \%$ female. 
During 2015-2019, the mean rate of hospitalizations and ED visits was highest for febrile convulsion (453 per 100,000 in children aged 0-4 years and 20.1 per 100,000 in children aged 511 years) and lowest for pericarditis ( 0.4 per 100,000 in both age groups). For children aged 0-4 years, the mean rates per 100,000 population for other AESI were 31.3 for idiopathic thrombocytopenia, 25.9 for Kawasaki disease, 8.8 for acute disseminated encephalomyelitis, 5.5 for Bell's palsy, 1.2 for myocarditis/pericarditis, 0.9 for myocarditis, 0.7 for Guillain-Barré syndrome, and 0.6 for transverse myelitis; the rates for children aged 5-11 years were 13.6 for idiopathic thrombocytopenia, 7.4 for Bell's palsy, 7.3 for Kawasaki disease, 4.1 for acute disseminated encephalomyelitis, 0.8 for myocarditis/pericarditis, and 0.6 for transverse myelitis and Guillain-Barré syndrome, 0.5 for myocarditis. When cases identified in outpatient physician offices were added, the mean rates per 100,000 population for Bell's palsy was 21.3 among children aged 0-4 years, and 17.4 among children aged 5-11 years.

The annual rates for most of the studied AESI fluctuated over the study period and were lower in 2020 than the mean annual rate during the pre-pandemic years (2015-2019) except for GuillainBarré syndrome among children aged 0-4 years and pericarditis among children aged 5-11 years (Supplemental Tables S2-S9). Rates of Kawasaki disease among children aged 0-4 years were 3-4 times higher than children aged 5-11 years.

Rates of idiopathic thrombocytopenia, febrile convulsions, and Kawasaki disease generally tended to be higher for males than females for both age groups (Supplemental Tables S3, S4, S7). In contrast, rates of hospitalizations, emergency department visits, and outpatient visits for Bell's palsy tended to be higher for females than males in children aged 5-11 years (Supplemental Table S2).

We noted seasonality for three AESI: Kawasaki disease peaked during November through March for children aged 0-4 years and during December and January for children aged 5-11 years; febrile convulsions peaked during December through March for children aged 0-4 years; and idiopathic thrombocytopenia among children aged 0-4 years peaked in December, January, and 
April when using the narrow definition and in December and January when using the broad definition (Figure 2).

\section{Discussion}

In this study, we estimated background rates of hospitalizations and emergency department visits for selected AESI in during 2015 to 2020 in Ontario. Our findings suggest that overall rates were generally consistent over time. Females had higher rates of acute disseminated encephalomyelitis and transverse myelitis while males had higher rates of myocarditis, pericarditis, and GuillainBarré syndrome. Bell's palsy, acute disseminated encephalomyelitis, and Guillain-Barré syndrome increased with age. Rates of pericarditis were higher than myocarditis. The rates of myocarditis and/or pericarditis increased with age until 79 years; and the rates were higher in males from 12-59 years for myocarditis and in males aged $\geq 12$ years, with two peaks for pericarditis. However, in children aged $<12$ years, rates varied during the pre-pandemic period and were lower in 2020 for most of these AESI. Males aged 0-11 years had higher rates of febrile convulsions, Kawasaki disease, and idiopathic thrombocytopenia than females aged 0-11 years, whereas females aged 5-11 years had higher rates of Bell's palsy than their male counterparts. Kawasaki disease and febrile convulsions tended to peak during the winter months.

We observed increased rates of Bell's palsy, Guillain-Barré syndrome, idiopathic thrombocytopenia and myocarditis and/or pericarditis with age similar to previous studies. ${ }^{35}$ Contrary to our finding, a gradual decrease in incidence of myocarditis with age in adults was reported in a previous study in Finland. ${ }^{36}$ We observed a higher rate in older children aged 16-19 years than younger children similar to other studies conducted in hospitalized children. ${ }^{37}$ Similar to our study, rates of myocarditis or pericarditis have been observed to increase with age with higher rates in males in a multinational study. ${ }^{35}$

Among children aged $<12$ years, compared to the mean rates during the pre-pandemic years, we observed lower rates in 2020 for most of these AESI except for Guillain-Barré syndrome in children aged 0-4 years, and pericarditis in children aged 5-11 years. The most striking absolute reduction in rate was observed for febrile convulsions in children aged 0-4 years. This likely resulted from the decreased circulation of non-COVID-19 respiratory viruses during the 
pandemic $^{38}$ as a result of broad public health measures in Ontario, including the lockdown in March-June 2020, continued province-wide mask mandate, and school-based strategies to ensure safe reopening of schools for in-person attendance in fall $2020 .{ }^{39}$ A decrease in healthcareseeking behaviours in 2020, along with surpassed hospital capacity at times of peak COVID-19 circulation, may also have caused some reduction in rates of hospital admissions or emergency department visits.

As expected, rates of Bell's palsy were higher when outpatient cases were added to cases that were hospitalized or sought care in emergency departments. However, the diagnostic code used to identify outpatient Bell's palsy cases from the physician billing claims also includes the diagnosis facial palsy. Consequently, the rates including outpatient cases may be an overestimate of the rate of Bell's palsy. The rate of Bell's palsy including outpatient and inpatient cases in US children aged $0-17$ years was reported to be 24 per 100,000 person-years. ${ }^{26}$ This rate is comparable to our estimated pre-pandemic mean rate for inpatient, ED visit, and outpatient cases for children aged $0-4$ years $(21.3$ per 100,000$)$ but higher than our rate for children aged 5-11 years (17.4 per 100,000). The background rate of Bell's palsy was reported to be 15 per 100,000 person-years in both males and females aged 1-5 years, and 25 and 21 per 100,000 person-years in females and males aged 6-17 years, respectively, in a recent multinational study using electronic health records and health claims data, including primary care data. ${ }^{35}$ The differences in the background rates between our study and other studies likely resulted from differences in calendar time, geography, population characteristics, distribution of risk factors, local transmission of possible causative viral infections, and healthcare systems.

Our estimated background rates of Kawasaki disease are within the previously reported range of 19.1-32.1 per 100,000 in Canadian children younger than 5 years of age ${ }^{32}$ and 5.1-50.4 per 100,000 in US children aged 0-6 years of age. ${ }^{40}$ Similar to those studies, we also observed higher rates for males than females among children aged 0-4 years. Our estimated pre-pandemic mean rates of GBS are similar to the rates reported in children aged 1-9 years in Denmark. ${ }^{41}$ Our mean rates of transverse myelitis are higher than the rates reported in children aged 1-9 years in Denmark (0.36 per 100,000 person-years for children aged 4-9 years) and Israel (0.40 per 100,000 person-years in children aged 0-9 years). ${ }^{2641}$ We observed seasonality for Kawasaki 
disease and febrile convulsions in young children with peak rates during the winter months conforming to previous reports. ${ }^{42} 43$

There are some limitations of this study. Our rates may be higher than those reported in the literature using hospitalization data alone as we also included cases treated in emergency departments. Imperfect validity of the diagnostic codes in administrative data without information on clinical and/or diagnostic confirmation may have resulted in under or overestimation. However, we used previously validated codes and/or codes that have been used in previous studies ${ }^{26} 3233$ to improve the accuracy of case ascertainment in administrative data. The quality of DAD hospitalization data has been previously evaluated. ${ }^{44}$ Our estimated rates may not be generalizable to other populations or settings because background rates are population-specific and differ by calendar time, population structure, distribution of risk factors, and healthcare systems. ${ }^{29}$

Our estimated background rates of hospitalizations and emergency department visits for the selected AESI in all age groups will facilitate estimating the number of expected events for these conditions. Reports of these AESI arising from Ontario's passive vaccine safety surveillance data can be compared to determine if they are greater than the expected number of events to assess potential safety signals. Additionally, our estimates suggest that some of these AESI are common in children aged $<12$ years and some have demonstrated seasonality. This information will further aid clinicians and public health authorities to gauge and contextualize higher observed events following immunization for these AESI.

\section{Contributors}

JCK, SN, NT, SEW conceived of the study design. JCK oversaw the study. AC prepared data and performed the statistical analysis. SN drafted the manuscript. All authors interpreted the results, critically revised the manuscript, and approved the final version.

\section{Funding}

This work was supported by the Canadian Immunization Research Network (CIRN) through a 
grant from the Public Health Agency of Canada and the Canadian Institutes of Health Research (CNF 151944). This study was also supported by ICES, which is funded by an annual grant from the Ontario Ministry of Health $(\mathrm{MOH})$. JCK is supported by a Clinician-Scientist Award from the University of Toronto Department of Family and Community Medicine. The analyses, conclusions, opinions and statements expressed herein are solely those of the authors and do not reflect those of the funding or data sources; no endorsement is intended or should be inferred.

\section{Conflict of interest}

The authors declare no conflicts of interest.

\section{Ethics approval}

ICES is a prescribed entity under Ontario’s Personal Health Information Protection Act (PHIPA). Section 45 of PHIPA authorizes ICES to collect personal health information, without consent, for the purpose of analysis or compiling statistical information with respect to the management of, evaluation or monitoring of, the allocation of resources to or planning for all or part of the health system. Projects that use data collected by ICES under section 45 of PHIPA, and use no other data, are exempt from REB review. The use of the data in this project is authorized under section 45 and approved by ICES' Privacy and Legal Office.

\section{Data availability statement}

The dataset from this study is held securely in coded form at ICES. While legal data sharing agreements between ICES and data providers (e.g., healthcare organizations and government) prohibit ICES from making the dataset publicly available, access may be granted to those who meet pre-specified criteria for confidential access, available at www.ices.on.ca/DAS (email: das@ices.on.ca). The full dataset creation plan and underlying analytic code are available from the authors upon request, understanding that the computer programs may rely upon coding templates or macros that are unique to ICES and are therefore either inaccessible or may require modification. 
medRxiv preprint doi: https://doi.org/10.1101/2022.01.12.22269169; this version posted January 16, 2022. The copyright holder for this preprint (which was not certified by peer review) is the author/funder, who has granted medRxiv a license to display the preprint in perpetuity.

It is made available under a CC-BY-NC-ND 4.0 International license .

\section{References:}

1. Health Canada. Drug and vaccine authorizations for COVID-19: List of applications received: Government of Canada; 2021 [Available from: https://www.canada.ca/en/healthcanada/services/drugs-health-products/covid19-industry/drugs-vaccinestreatments/authorization/applications.html accessed 23 November 2021.

2. Health Canada. Drug and vaccine authorizations for COVID-19: List of authorized drugs, vaccines and expanded indications: Government of Canada; 2021 [Available from: https://www.canada.ca/en/health-canada/services/drugs-health-products/covid19industry/drugs-vaccines-treatments/authorization/list-drugs.html\#wb-auto-4 accessed 23 November 2021.

3. Canada H. Drug and vaccine authorizations for COVID-19: List of authorized drugs, vaccines and expanded indications Ottawa, ON: Government of Canada; 2021 [Available from: https://www.canada.ca/en/health-canada/services/drugs-health-products/covid19industry/drugs-vaccines-treatments/authorization/list-drugs.html accessed 19 March 2021.

4. Ontario Agency for Health Protection and Promotion (Public Health Ontario). COVID-19 viral vector vaccines and rare blood clots - vaccine safety surveillance in action Toronto, ON: Queen's Printer for Ontario; 2021 [Available from: https://www.publichealthontario.ca/-/media/documents/ncov/vaccines/2021/07/covid-19viral-vector-vaccines-rare-blood-clots.pdf?sc lang=en accessed 6 June 2021.

5. Medicines and Healthcare products Regulatory Agency (MHRA). Coronavirus vaccine weekly summary of Yellow Card reporting [Internet]. London (UK): Department of Health and Social Care 2021 [Available from:

https://www.gov.uk/government/publications/coronavirus-covid-19-vaccine-adversereactions/coronavirus-vaccine-summary-of-yellow-card-reporting accessed, 26 October 2021.

6. Therapeutic Goods Administration (TGA). COVID-19 vaccine weekly safety report [Internet] Canberra: Department of Health, Australian Government; 2021 [Available from: https://www.tga.gov.au/periodic/covid-19-vaccine-weekly-safety-report-14-10-2021 accessed, 26 October 2021.

7. World Health Organization (WHO). COVID-19 subcommittee of the WHO Global Advisory Committee on Vaccine Safety (GACVS) reviews cases of mild myocarditis reported with COVID-19 mRNA vaccines [Internet] Geneva: WHO; 2021 [Available from: https://www.who.int/news/item/26-05-2021-gacvs-myocarditis-reported-with-covid-19mrna-vaccines accessed, 14 June 2021.

8. Gov.il. Surveillance of myocarditis (inflammation of the heart muscle) cases between December 2020 and May 2021 (including). Press release [Internet] Israel: Ministry of Health; 2021 [Available from: https://www.gov.il/en/departments/news/01062021-03 accessed, 26 October 2021.

9. Shimabukuro T. COVID-19 Vaccine Safety Updates. Vaccines and Related Biological Products. Advisory Committee (VRBPAC). [VRBPAC meeting presentation] [Internet] Atlanta: United States Centers for Disease Control and Prevention (CDC), COVID-19 Vaccine Task Force; 2021 [Available from: https://www.fda.gov/media/150054/download accessed, 20 June 2021.

10. European Medicines Agency (EMA). COVID-19 vaccines: update on ongoing evaluation of myocarditis and pericarditis [Internet] Amsterdam: EMA; 2021 [Available from: 
medRxiv preprint doi: https://doi.org/10.1101/2022.01.12.22269169; this version posted January 16, 2022. The copyright holder for this preprint (which was not certified by peer review) is the author/funder, who has granted medRxiv a license to display the preprint in perpetuity. It is made available under a CC-BY-NC-ND 4.0 International license .

https://www.ema.europa.eu/en/news/covid-19-vaccines-update-ongoing-evaluationmyocarditis-pericarditis accessed, 20 June 2021.

11. Ontario Agency for Health Protection and Promotion (Public Health Ontario). Adverse Events Following Immunization (AEFIs) for COVID-19 in Ontario: December 13, 2020 to October 17, 2021 Toronto, ON: Queen's Printer for Ontario; 2021 [Available from: https://www.publichealthontario.ca/-/media/documents/ncov/epi/covid-19-aefireport.pdf?sc_lang=en accessed, 26 October 2021.

12. Marshall M, Ferguson ID, Lewis $P$, et al. Symptomatic Acute Myocarditis in 7 Adolescents After Pfizer-BioNTech COVID-19 Vaccination. Pediatrics 2021;148(3) doi: 10.1542/peds.2021-052478 [published Online First: 2021/06/06]

13. Rosner CM, Genovese L, Tehrani BN, et al. Myocarditis Temporally Associated With COVID-19 Vaccination. Circulation 2021;144(6):502-05. doi: 10.1161/circulationaha.121.055891 [published Online First: 2021/06/17]

14. Bozkurt B, Kamat I, Hotez PJ. Myocarditis With COVID-19 mRNA Vaccines. Circulation 2021;144(6):471-84. doi: 10.1161/CIRCULATIONAHA.121.056135

15. Buchan SA, Seo CY, Johnson C, et al. Epidemiology of myocarditis and pericarditis following mRNA vaccines in Ontario, Canada: by vaccine product, schedule and interval. medRxiv 2021:2021.12.02.21267156. doi: 10.1101/2021.12.02.21267156

16. Abraham N, Spruin S, Rossi T, et al. Myocarditis and/or Pericarditis Risk After mRNA COVID-19 Vaccination: A Canadian Head to Head Comparison of BNT162b2 and mRNA-1273 Vaccines. JVAC-D-21-03106 2021:Available at SSRN: https://ssrn.com/abstract=3988612.

17. Renoud L, Khouri C, Revol B, et al. Association of Facial Paralysis With mRNA COVID-19 Vaccines: A Disproportionality Analysis Using the World Health Organization Pharmacovigilance Database. JAMA Intern Med 2021;181(9):1243-45. doi: 10.1001/jamainternmed.2021.2219

18. World Health Organization. Statement of the WHO Global Advisory Committee on Vaccine Safety (GACVS) COVID-19 subcommittee on reports of Guillain-Barré Syndrome (GBS) following adenovirus vector COVID-19 vaccines 2021 [Available from: https://www.who.int/news/item/26-07-2021-statement-of-the-who-gacvs-covid-19subcommittee-on-gbs accessed 10 August, 2021.

19. European Medicines Agency (EMA). COVID-19 vaccine safety update VAXZEVRIA AstraZeneca AB Public Statement 2021 [Available from: https://www.ema.europa.eu/en/documents/covid-19-vaccine-safety-update/covid-19vaccine-safety-update-vaxzevria-previously-covid-19-vaccine-astrazeneca-14-july2021_en.pdf accessed 10 August, 2021.

20. Advisory Committee on Immunization Practices (ACIP). Guillain-Barré Syndrome (GBS) after Janssen COVID-19 Vaccine: Vaccine Adverse Event Reporting System (VAERS). Meeting of the Advisory Committee on Immunization Practices (ACIP), July 22, 2021. 2021

21. Food and Drug Administration (FDA). Vaccines and Related Biological Products Advisory Committee October 26, 2021 Meeting Document. BNT162B2 [COMIRNATY (COVID19 VACCINE, MRNA)]: Food and Drug Administration (FDA); 2021 [Available from: https://www.fda.gov/media/153409/download accessed, 26 October 2021.

22. Centers for Disease Control and Prevention (CDC). CDC Recommends Pediatric COVID-19 Vaccine for Children 5 to 11 Years 2021 [Available from: 
medRxiv preprint doi: https://doi.org/10.1101/2022.01.12.22269169; this version posted January 16, 2022. The copyright holder for this preprint (which was not certified by peer review) is the author/funder, who has granted medRxiv a license to display the preprint in perpetuity.

It is made available under a CC-BY-NC-ND 4.0 International license .

https://www.cdc.gov/media/releases/2021/s1102-PediatricCOVID-19Vaccine.html accessed 3 November 2021,.

23. Health Canada. Health Canada authorizes use of Comirnaty (the Pfizer-BioNTech COVID19 vaccine) in children 5 to 11 years of age: Government of Canada; 2021 [Available from: https://www.canada.ca/en/health-canada/news/2021/11/health-canada-authorizesuse-of-comirnaty-the-pfizer-biontech-covid-19-vaccine-in-children-5-to-11-years-ofage.html accessed 19 November 2021.

24. National Advisory Committee on Immunization (NACI). An Advisory Committee Statement (ACS) National Advisory Committee on Immunization (NACI). Recommendation on the use of the Pfizer-BioNTech COVID-19 vaccine $(10 \mathrm{mcg})$ in children 5-11 years of age. Ottawa, ON: Government of Canada; 2021 [Available from:

https://www.canada.ca/content/dam/phacaspc/documents/services/immunization/national-advisory-committee-on-immunizationnaci/recommendations-use-covid-19-vaccines/pfizer-biontech-10-mcg-children-5-11years-age/pfizer-biontech-10-mcg-children-5-11-years-age.pdf accessed 19 November 2021.

25. Lopalco PL, DeStefano F. The complementary roles of Phase 3 trials and post-licensure surveillance in the evaluation of new vaccines. Vaccine 2015;33(13):1541-48. doi: https://doi.org/10.1016/j.vaccine.2014.10.047

26. Black S, Eskola J, Siegrist C-A, et al. Importance of background rates of disease in assessment of vaccine safety during mass immunisation with pandemic H1N1 influenza vaccines. Lancet 2009;374(9707):2115-22. doi: 10.1016/S0140-6736(09)61877-8

27. Deeks SL, Lim GH, Simpson MA, et al. Estimating background rates of Guillain-Barre Syndrome in Ontario in order to respond to safety concerns during pandemic H1N1/09 immunization campaign. BMC Public Health 2011;11:329. doi: 10.1186/1471-2458-11329

28. Wang Y, Wu L, Yu X, et al. The Expected Number of Background Disease Events during Mass Immunization in China. PLoS One 2013;8(8):e71818. doi:

10.1371/journal.pone.0071818

29. Black SB, Law B, Chen RT, et al. The Critical Role Background Rates of Possible Adverse Events in the Assessment of COVID-19 Vaccine Safety. Vaccine 2021 doi: https://doi.org/10.1016/j.vaccine.2021.03.016

30. Nasreen S, Calzavara AJ, Sundaram ME, et al. Background incidence rates of hospitalisations and emergency department visits for thromboembolic and coagulation disorders in Ontario, Canada for COVID-19 vaccine safety assessment: a populationbased retrospective observational study. BMJ Open 2021;11(12):e052019. doi: 10.1136/bmjopen-2021-052019 [published Online First: 2021/12/19]

31. International statistical classification of diseases and related health problems, tenth revision, Canada (ICD-10-CA). Ottawa, Ontario, Canada: Canadian Institute for Health Information, 2018.

32. Wormsbecker AE, Johnson C, Bourns L, et al. Demonstration of background rates of three conditions of interest for vaccine safety surveillance. PLoS One 2019;14(1):e0210833. doi: 10.1371/journal.pone.0210833

33. Willame C, Dodd C, Gini R, et al. Background rates of Adverse Events of Special Interest for monitoring COVID-19 vaccines (2.0). Zenodo 2021 doi:

https://doi.org/10.5281/zenodo.5255870 
medRxiv preprint doi: https://doi.org/10.1101/2022.01.12.22269169; this version posted January 16, 2022. The copyright holder for this preprint (which was not certified by peer review) is the author/funder, who has granted medRxiv a license to display the preprint in perpetuity.

It is made available under a CC-BY-NC-ND 4.0 International license .

34. Fay MP, Feuer EJ. Confidence intervals for directly standardized rates: a method based on the gamma distribution. Stat Med 1997;16(7):791-801. doi: 10.1002/(sici)10970258(19970415)16:7

35. Li X, Ostropolets A, Makadia R, et al. Characterising the background incidence rates of adverse events of special interest for covid-19 vaccines in eight countries: multinational network cohort study. BMJ 2021;373:n1435. doi: 10.1136/bmj.n1435

36. Kytö V, Sipilä J, Rautava P. The effects of gender and age on occurrence of clinically suspected myocarditis in adulthood. Heart 2013;99(22):1681-4. doi: 10.1136/heartjnl2013-304449 [published Online First: 2013/09/26]

37. Vasudeva R, Bhatt P, Lilje C, et al. Trends in Acute Myocarditis Related Pediatric Hospitalizations in the United States, 2007-2016. Am J Cardiol 2021;149:95-102. doi: https://doi.org/10.1016/j.amjcard.2021.03.019

38. Ontario Agency for Health Protection and Promotion (Public Health Ontario). Ontario respiratory pathogen bulletin [Internet]. Toronto, ON: Queen's Printer for Ontario; 2021 [Available from: https://www.publichealthontario.ca/en/data-and-analysis/infectiousdisease/respiratory-pathogens-weekly/respiratory-pathogens-historical accessed November 252021.

39. Government of Ontario. Guide to reopening Ontario's schools: Queen's Printer for Ontario; 2020 [Available from: https://www.ontario.ca/page/guide-reopening-ontarios-schools accessed November 252021.

40. Gubernot D, Jazwa A, Niu M, et al. U.S. Population-Based background incidence rates of medical conditions for use in safety assessment of COVID-19 vaccines. Vaccine 2021;39(28):3666-77. doi: 10.1016/j.vaccine.2021.05.016

41. Rasmussen TA, Jørgensen MRS, Bjerrum S, et al. Use of population based background rates of disease to assess vaccine safety in childhood and mass immunisation in Denmark: nationwide population based cohort study. BMJ 2012;345:e5823. doi: 10.1136/bmj.e5823

42. Burns JC, Herzog L, Fabri O, et al. Seasonality of Kawasaki disease: a global perspective. PLoS One 2013;8(9):e74529-e29. doi: 10.1371/journal.pone.0074529

43. Mikkonen K, Uhari M, Pokka T, et al. Diurnal and seasonal occurrence of febrile seizures. Pediatr Neurol 2015;52(4):424-7. doi: 10.1016/j.pediatrneurol.2015.01.001 [published Online First: 2015/02/16]

44. Juurlink D, Preyra C, Croxford R, et al. Canadian Institute for Health Information Discharge Abstract Database: A Validation Study Toronto: Institute for Clinical Evaluative Sciences; 2006 [Available from: https://www.ices.on.ca/flip-publication/canadianistitute-for-health-information-discharge/files/assets/basic-html/index.html\#9. 
Tables and figures:

Table 1: Annual background rates of adverse events of special interest (AESI) in Ontario from 2015 to 2020

\begin{tabular}{|c|c|c|c|c|c|c|c|}
\hline \multirow[t]{2}{*}{ Year } & \multicolumn{7}{|c|}{ Incidence rate per 100,000 population ( $95 \%$ confidence interval) } \\
\hline & Bell's palsy & $\begin{array}{c}\text { Bell's palsy } \\
\text { (including } \\
\text { outpatient visits) }\end{array}$ & $\begin{array}{c}\text { ITP, narrow } \\
\text { definition }\end{array}$ & $\begin{array}{l}\text { ITP, broad } \\
\text { definition }\end{array}$ & $\begin{array}{c}\text { Febrile } \\
\text { convulsions }\end{array}$ & $\begin{array}{c}\text { ADEM, narrow } \\
\text { definition }\end{array}$ & $\begin{array}{c}\text { ADEM, broad } \\
\text { definition }\end{array}$ \\
\hline 2015 & $\begin{array}{c}27.0 \\
(26.1,27.9)\end{array}$ & $\begin{array}{c}71.3 \\
(69.9,72.8)\end{array}$ & $\begin{array}{c}6.41 \\
(6.00,6.85)\end{array}$ & $\begin{array}{c}40.5 \\
(39.4,41.5)\end{array}$ & $\begin{array}{c}23.5 \\
(22.7,24.3)\end{array}$ & $\begin{array}{c}0.16 \\
(0.10,0.24)\end{array}$ & $\begin{array}{c}21.8 \\
(21.1,22.6)\end{array}$ \\
\hline 2016 & $\begin{array}{c}27.0 \\
(26.1,27.9)\end{array}$ & $\begin{array}{c}71.7 \\
(70.3,73.1)\end{array}$ & $\begin{array}{c}6.31 \\
(5.90,6.74)\end{array}$ & $\begin{array}{c}43.5 \\
(42.4,44.6)\end{array}$ & $\begin{array}{c}28.57 \\
(27.7,29.5)\end{array}$ & $\begin{array}{c}0.22 \\
(0.15,0.31)\end{array}$ & $\begin{array}{c}23.0 \\
(22.2,23.8)\end{array}$ \\
\hline 2017 & $\begin{array}{c}27.9 \\
(27.0,28.7)\end{array}$ & $\begin{array}{c}72.0 \\
(70.6,73.4)\end{array}$ & $\begin{array}{c}6.14 \\
(5.74,6.56)\end{array}$ & $\begin{array}{c}44.8 \\
(43.7,45.9)\end{array}$ & $\begin{array}{c}23.7 \\
(22.9,24.5)\end{array}$ & $\begin{array}{c}0.22 \\
(0.15,0.31)\end{array}$ & $\begin{array}{c}23.2 \\
(22.4,24.0)\end{array}$ \\
\hline 2018 & $\begin{array}{c}27.9 \\
(27.0,28.7)\end{array}$ & $\begin{array}{c}70.9 \\
(69.6,72.3)\end{array}$ & $\begin{array}{c}5.75 \\
(5.37,6.16)\end{array}$ & $\begin{array}{c}44.9 \\
(43.8,46.0)\end{array}$ & $\begin{array}{c}25.5 \\
(24.6,26.3)\end{array}$ & $\begin{array}{c}0.20 \\
(0.13,0.28)\end{array}$ & $\begin{array}{c}23.0 \\
(22.2,23.8)\end{array}$ \\
\hline 2019 & $\begin{array}{c}29.2 \\
(28.3,30.1)\end{array}$ & $\begin{array}{c}70.6 \\
(69.2,72.0)\end{array}$ & $\begin{array}{c}5.81 \\
(5.42,6.21)\end{array}$ & $\begin{array}{c}45.8 \\
(44.8,47.0)\end{array}$ & $\begin{array}{c}24.0 \\
(23.2,24.8)\end{array}$ & $\begin{array}{c}0.14 \\
(0.09,0.22)\end{array}$ & $\begin{array}{c}22.9 \\
(22.1,23.7)\end{array}$ \\
\hline 2020 & $\begin{array}{c}31.4 \\
(30.5,32.3) \\
\end{array}$ & $\begin{array}{c}70.5 \\
(69.1,71.9) \\
\end{array}$ & $\begin{array}{c}4.54 \\
(4.20,4.90) \\
\end{array}$ & $\begin{array}{c}46.5 \\
(45.4,47.6) \\
\end{array}$ & $\begin{array}{c}13.5 \\
(12.9,14.1) \\
\end{array}$ & $\begin{array}{c}0.10 \\
(0.06,0.17) \\
\end{array}$ & $\begin{array}{c}20.1 \\
(19.4,20.8) \\
\end{array}$ \\
\hline Year & $\begin{array}{c}\text { Myocarditis/peri } \\
\text { carditis }\end{array}$ & Myocarditis & Pericarditis & Kawasaki disease & $\begin{array}{c}\text { Guillain-Barré } \\
\text { syndrome }\end{array}$ & $\begin{array}{c}\text { Transverse } \\
\text { myelitis, narrow } \\
\text { definition }\end{array}$ & $\begin{array}{c}\text { Transverse } \\
\text { myelitis, broad } \\
\text { definition }\end{array}$ \\
\hline 2015 & $\begin{array}{c}9.82 \\
(9.30,10.36)\end{array}$ & $\begin{array}{c}2.54 \\
(2.28,2.82)\end{array}$ & $\begin{array}{c}7.53 \\
(7.08,8.00)\end{array}$ & $\begin{array}{c}1.96 \\
(1.73,2.21)\end{array}$ & $\begin{array}{c}1.83 \\
(1.61,2.07)\end{array}$ & $\begin{array}{c}0.61 \\
(0.49,0.76)\end{array}$ & $\begin{array}{c}1.27 \\
(1.09,1.47)\end{array}$ \\
\hline 2016 & $\begin{array}{c}10.22 \\
(9.69,10.77)\end{array}$ & $\begin{array}{c}2.88 \\
(2.60,3.17)\end{array}$ & $\begin{array}{c}7.64 \\
(7.19,8.11)\end{array}$ & $\begin{array}{c}2.00 \\
(1.77,2.25)\end{array}$ & $\begin{array}{c}1.94 \\
(1.71,2.18)\end{array}$ & $\begin{array}{c}0.90 \\
(0.75,1.07)\end{array}$ & $\begin{array}{c}1.84 \\
(1.63,2.09)\end{array}$ \\
\hline 2017 & $\begin{array}{c}12.4 \\
(11.8,13.0)\end{array}$ & $\begin{array}{c}3.38 \\
(3.08,3.69)\end{array}$ & $\begin{array}{c}9.35 \\
(8.85,9.87)\end{array}$ & $\begin{array}{c}2.03 \\
(1.80,2.27)\end{array}$ & $\begin{array}{c}1.83 \\
(1.61,2.06)\end{array}$ & $\begin{array}{c}0.73 \\
(0.60,0.89)\end{array}$ & $\begin{array}{c}1.69 \\
(1.48,1.92)\end{array}$ \\
\hline 2018 & $\begin{array}{c}11.9 \\
(11.3,12.4)\end{array}$ & $\begin{array}{c}2.58 \\
(2.32,2.86)\end{array}$ & $\begin{array}{c}9.44 \\
(8.94,9.96)\end{array}$ & $\begin{array}{c}2.15 \\
(1.92,2.41)\end{array}$ & $\begin{array}{c}1.88 \\
(1.66,2.12)\end{array}$ & $\begin{array}{c}0.85 \\
(0.71,1.02)\end{array}$ & $\begin{array}{c}1.81 \\
(1.60,2.04)\end{array}$ \\
\hline 2019 & $\begin{array}{c}12.0 \\
(11.4,12.6)\end{array}$ & $\begin{array}{c}2.93 \\
(2.66,3.22)\end{array}$ & $\begin{array}{c}9.24 \\
(8.75,9.75)\end{array}$ & $\begin{array}{c}1.71 \\
(1.51,1.94)\end{array}$ & $\begin{array}{c}1.82 \\
(1.60,2.05)\end{array}$ & $\begin{array}{c}0.87 \\
(0.73,1.04)\end{array}$ & $\begin{array}{c}1.95 \\
(1.73,2.19)\end{array}$ \\
\hline 2020 & $\begin{array}{c}10.7 \\
(10.2,11.2)\end{array}$ & $\begin{array}{c}2.42 \\
(2.18,2.69)\end{array}$ & $\begin{array}{c}8.44 \\
(7.97,8.92) \\
\end{array}$ & $\begin{array}{c}1.55 \\
(1.35,1.76)\end{array}$ & $\begin{array}{c}1.34 \\
(1.16,1.54)\end{array}$ & $\begin{array}{c}0.83 \\
(0.69,1.00) \\
\end{array}$ & $\begin{array}{c}1.93 \\
(1.71,2.17)\end{array}$ \\
\hline
\end{tabular}

$\mathrm{ADEM}=$ Acute disseminated encephalomyelitis, ITP $=$ Idiopathic thrombocytopenia 


\section{Figures:}

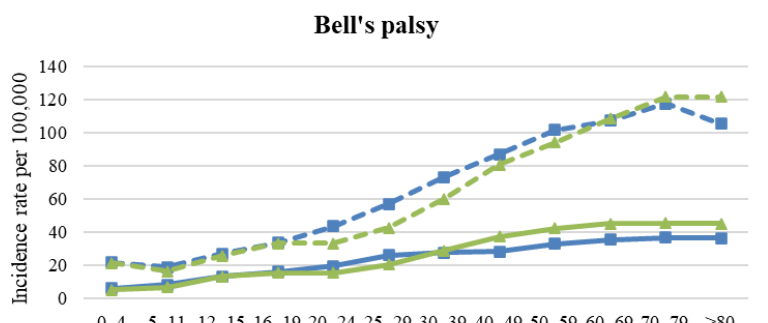

$$
\text { Age group (years) }
$$

$$
\longrightarrow \text { Females } \quad \longrightarrow \text { Males }
$$

$-{ }_{-1}-$ Females, including outpatient visits $-\$-$ Males, including outpatient visits

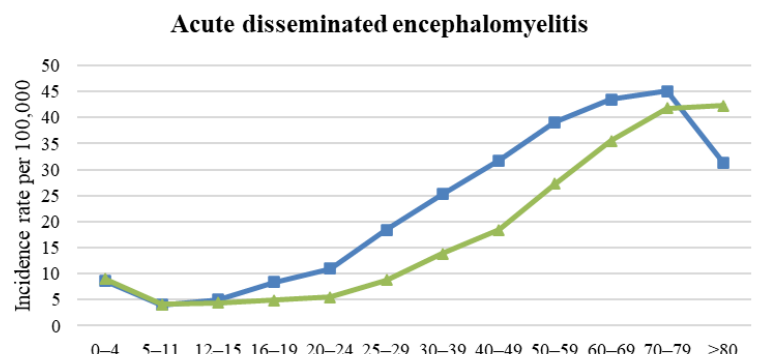

0-4 $\quad 5-11 \quad 12-15 \quad 16-1920-24 \quad 25-29 \quad 30-3940-4950-59 \quad 60-69$ 70-79 $\geq 80$ Age group (years)

$\rightarrow$ Females $\leftrightharpoons$ Males

Kawasaki disease

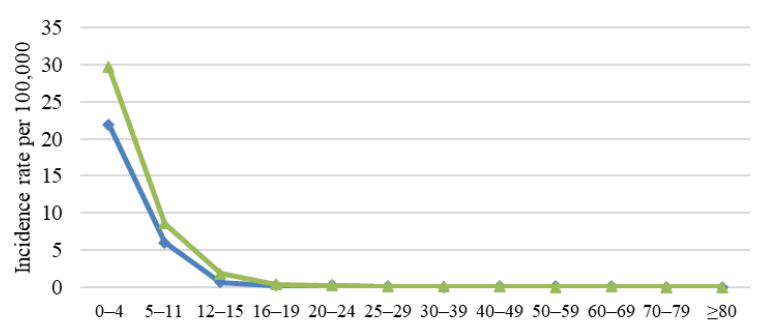

Age group (years)

$\leftarrow$ Females $\simeq$ Males

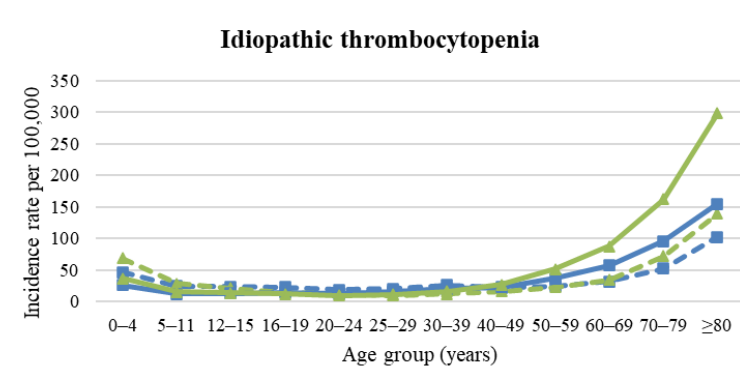

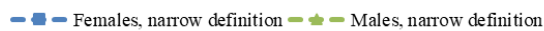

- - Females, broad definition $\longrightarrow$ Males, broad definition

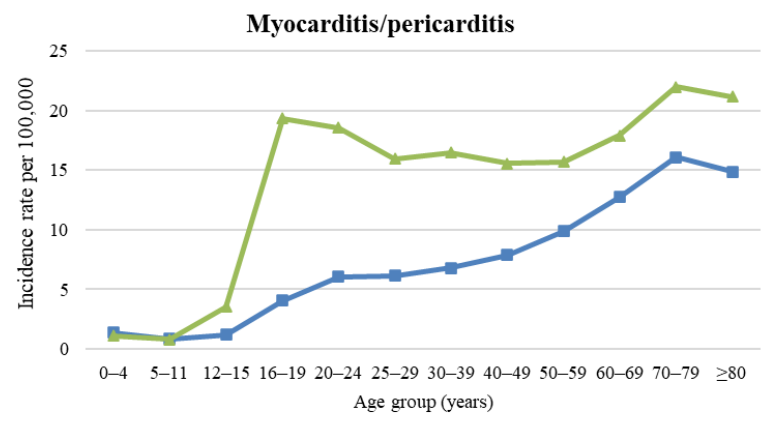

$\triangle$-Myocarditis/pericarditis, females $\quad \longrightarrow$ Myocarditis/pericarditis, males

Guillain-Barré syndrome

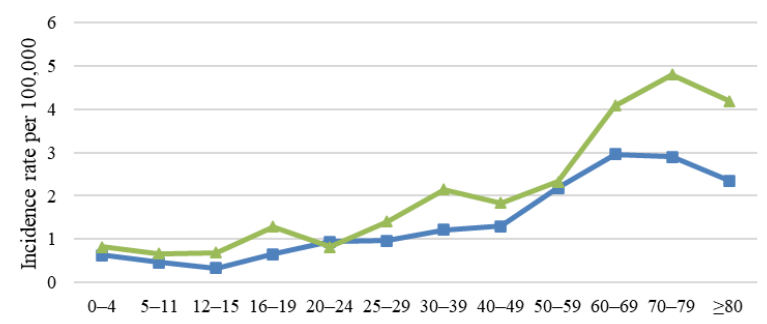

Age group (years)

$\rightarrow$ Females $\longrightarrow$ Males

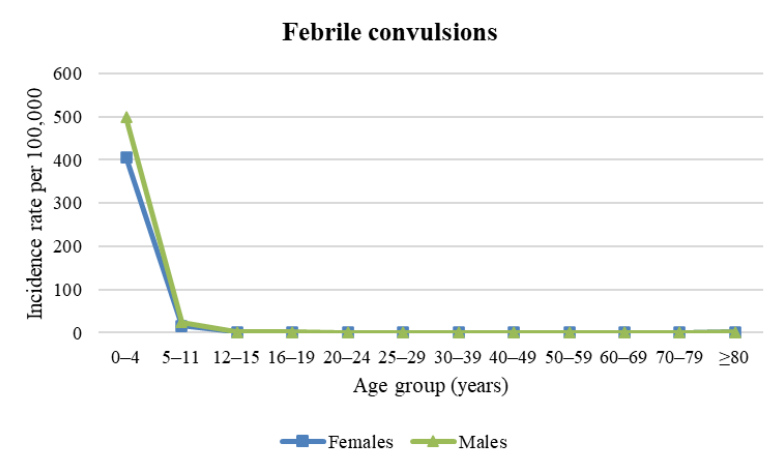

Myocarditis and pericarditis

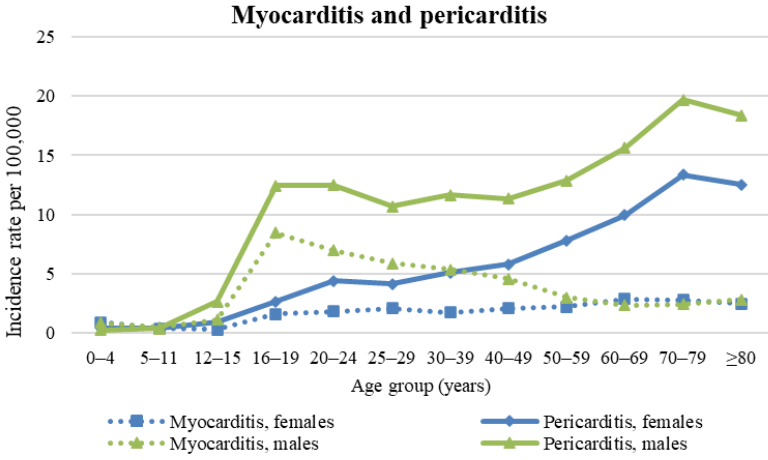

Transverse myelitis

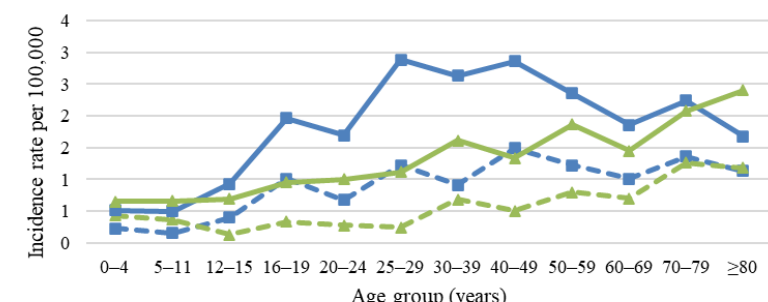
Age group (years)

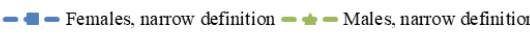
$\longrightarrow$-Females, broad definition $\longrightarrow$ Males, broad definition

Figure 1: Age and sex stratified mean annual background rates (per 100,000 population) for nine adverse events of special interest in Ontario, 2015 to 2019 

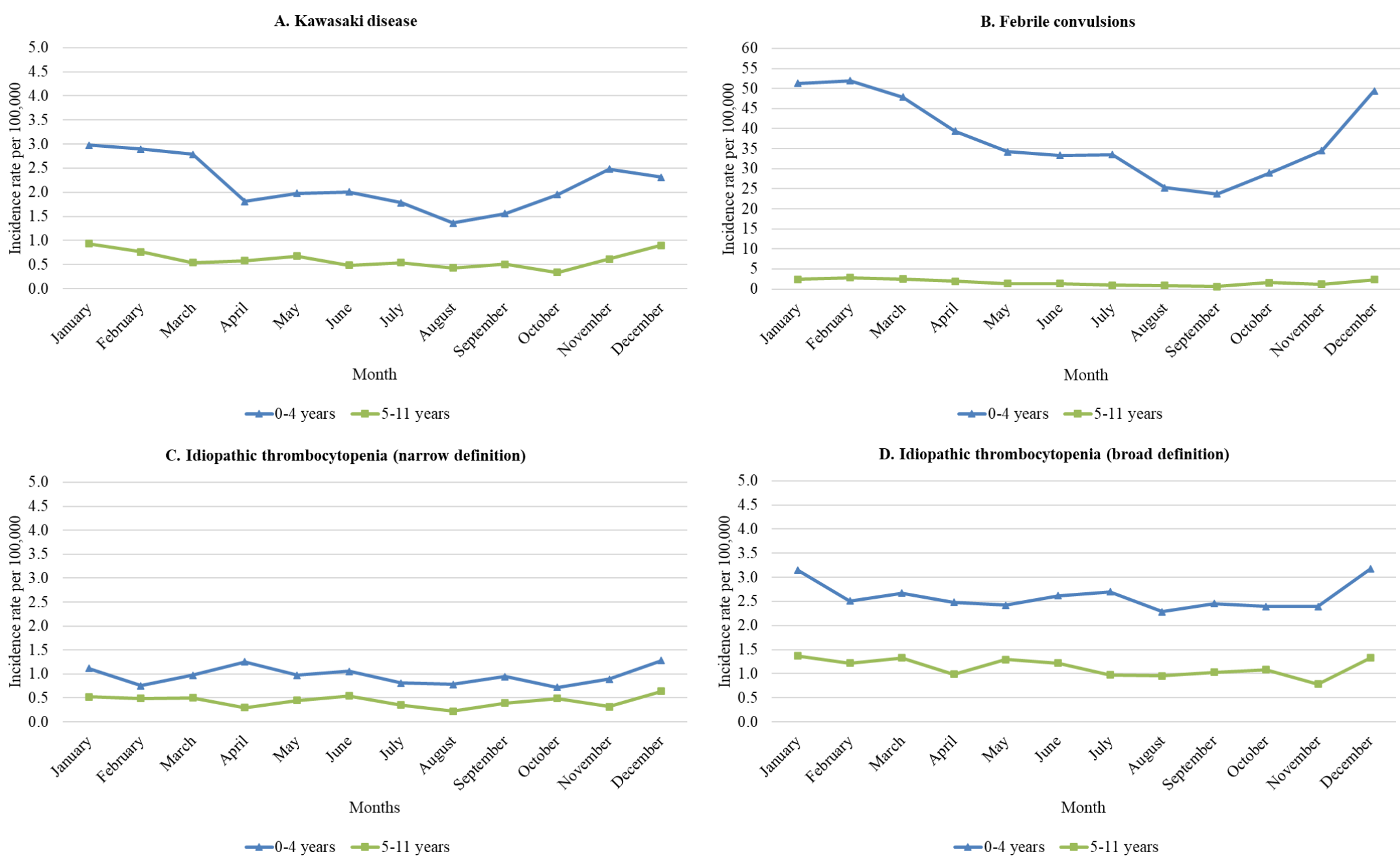

Figure 2: Monthly average incidence rates of hospitalization and emergency department visits in Ontario, 2015 to 2020: A. Kawasaki disease, B. Febrile convulsions, C. Idiopathic thrombocytopenia (narrow definition), D. Idiopathic thrombocytopenia (broad definition). 